\title{
Miguel Bahl: uma síntese do seu legado para o turismo ${ }^{1}$
}

\author{
Bruno Martins Augusto Gomes ${ }^{2}$ \\ Letícia Bartoszek Nitsche ${ }^{3}$ \\ Margarete Araújo Teles ${ }^{4}$ \\ Silvana do Rocio de Souza ${ }^{5}$
}

Esse primeiro número do ano 2019 da revista Turismo e Sociedade (volume 12) tem uma marca histórica. Sua organização foi iniciada pelo professor Miguel Bahl, fundador da revista. Mas em face do seu repentino falecimento, ocorrido em 2 de agosto de 2019, ao retornar de uma viagem e desenvolver um processo de infecção pulmonar, essa edição foi conduzida e concluída pelos colegas e amigos do grupo de pesquisa Turismo e Sociedade. Os membros do grupo já atuavam na revista, dentre eles o atual editor-chefe, professor Bruno Martins Augusto Gomes, que já exercia a função de editor adjunto. Todavia, na revista, assim como no Departamento de Turismo e em outras instâncias da Universidade Federal do Paraná, o professor Miguel era o maestro.

Assim, os pesquisadores do grupo Turismo e Sociedade, diante da inesperada partida deste colega e amigo, se sentiram impelidos a dar continuidade à edição da revista Turismo e Sociedade. Cientes dos desafios inerentes à edição de uma revista gratuita, os quais se intensificam com o acúmulo de tarefas característico dos professores e pesquisadores em dedicação exclusiva nas universidades públicas brasileiras, assumiram o encargo, imbuídos pela necessidade de dar continuidade ao trabalho de dedicação à Revista de acordo com alguns dos ensinamentos deixados pelo professor Miguel Bahl.

A revista Turismo e Sociedade tinha um significado especial para ele. Não obstante ser a implantação de uma revista científica sua aspiração desde o início dos anos

\footnotetext{
${ }^{1}$ Texto elaborado com a colaboração de Cleunice Fritoli e Vera Bahl.

2345 Professores do Departamento de Turismo da Universidade Federal do Paraná (UFPR), membros do Conselho Editorial da Revista Turismo e Sociedade.
} 
2000, que se concretizou em 2008, vinculada ao Departamento de Turismo da UFPR, a revista tornou-se um veículo de grande contribuição para a disseminação de conhecimento da comunidade científica do turismo, tendo publicado mais de duzentos e cinquenta artigos científicos.

Como em tudo que o professor Miguel Bahl se envolveu ao longo de sua vida profissional, a sua dedicação à revista foi intensa, lhe custando finais de semanas e férias. Mas dada a sua paixão pela área acadêmica do turismo, aliada à sabedoria que apenas a experiência de longos anos em uma universidade pública pode proporcionar, ele manifestava que cumpria a sua missão de editor com um sentimento de cooperação em relação aos autores na divulgação do conhecimento produzido por eles, assumindo essa nobre tarefa um significado de hobby em sua vida, conforme suas próprias palavras.

Diante desse contexto, o Conselho Editorial da revista, formado pelos professores Bruno Martins Augusto Gomes, Letícia Bartoszek Nitsche, Margarete Araújo Teles e Silvana do Rocio de Souza, homenageia o professor Miguel Bahl nesse número da revista. Para tanto, a melhor maneira é relembrar a trajetória e o legado para o ensino, a pesquisa e a extensão em turismo desse ilustre curitibano que nos brindou com sua sabedoria e com sua capacidade de planejamento e de organização.

A biografia do professor Miguel Bahl, exposta a seguir, foi em grande parte obtida por meio do texto escrito por esse filho de sapateiro e costureira quando de sua candidatura, com êxito, à mais alta posição na carreira docente das universidades federais brasileiras, a de professor titular.

Os seus pais, profissionais autônomos, eram grandes incentivadores para que os filhos buscassem aprimorar seus conhecimentos, estudar e obter o título acadêmico. De acordo com a percepção deles, as mudanças sociais e econômicas dos países iriam requerer profissionais de cultura e formação escolar mais ampla, de maneira que somente a educação básica não seria suficiente para vencer as demandas dos contextos. Assim, seus pais, Pedro e Cremilda Bahl, com a sabedoria que não se alcança somente nos bancos escolares, "sempre estimularam os filhos a estudarem e se aprimorarem considerando ser este um dos maiores patrimônios para um ser humano" (BAHL, 2004, p. 1).

Residindo desde o nascimento no bairro Rebouças, em Curitiba, e tendo a companhia de dois irmãos, Jurandir Bahl e Pedro Bahl, e uma irmã, Vera Bahl, ele sempre estudou em instituições de ensino públicas, desde o antigo primário e colegial, graduação 
e pós-graduação. Enquanto aluno da Educação Básica (Primário até o Colegial), atuava como aprendiz de sapateiro do seu pai, o que rendia a ele um valor suficiente para a compra das passagens do ônibus entre a sua casa e o colégio. Ao terminar o colegial recebeu a responsabilidade repassada pelo seu pai de que teria que trabalhar para continuar a estudar, pois não teria condições para custear o curso preparatório para o vestibular ou mesmo uma universidade particular.

O seu primeiro emprego foi de mensageiro na Ordem dos Advogados do Brasil, meio expediente, o que lhe possibilitou frequentar aulas à noite e estudar pela manhã. Nas palavras do professor Miguel Bahl (2004, p. 1):

Gostei muito de ter atuado como mensageiro, pois passei a conhecer a cidade de Curitiba, a sua distribuição física e espacial, bem como a sua estrutura de transportes, que no futuro acabaria por agregar conhecimento e bagagem para a minha atual atividade associada ao planejamento, organização e gestão do turismo.

Em seu primeiro vestibular considerou que a Arquitetura seria a área de preferência, ficando dividido, ainda, entre Agronomia e Engenharia Florestal. Nem de longe imaginava que deveria seguir suas preferências ou gostos pessoais que estavam alinhados à Geografia Humana, descrição, análise, percepção e distribuição espacial. No segundo vestibular passou nas provas e entrou no Curso de Geografia, como primeiro colocado, com um escore que teria permitido sua aprovação em vários outros cursos.

Ao iniciar o curso percebeu que não teria condições de continuar estudando, pois o mesmo era diurno e ele precisava se sustentar. Na época, já era servidor público concursado, trabalhando no Instituto Nacional de Assistência Médica e de Previdência Social (INAMPS), e não havia como conciliar os horários. Assim, procurou concluir as disciplinas que possibilitavam obter o título de licenciado em Estudos Sociais na UFPR.

Em seguida, a partir da identificação da instalação do Curso de Turismo na UFPR, pediu o aproveitamento de curso e passou a cursá-lo em 1981. Esta solicitação se originou da descoberta, enquanto aluno do curso de Geografia, da pertinência das viagens para o aprendizado. Em paralelo, a licenciatura curta em Estudos Sociais lhe possibilitou atuar no magistério em escolas públicas municipais de Curitiba. Nestas atividades, planejava e levava as crianças para visitarem os museus de Curitiba, e elas, ao retornarem, expressavam nos desenhos a experiência que viviam. Como professor teve a oportunidade 
de alfabetizar uma turma de alunos o que, segundo relatado pelo professor Miguel, foi um trabalho pelo qual tinha muita estima:

Foi muito importante atuar com crianças, pois aprendi uma outra forma de relação com a vida e a responsabilidade enquanto cidadão em propiciar o melhor de mim para aqueles que seriam os futuros cidadãos deste nosso país tão rico em diversidade. Faço esta colocação, pois trabalhei com crianças pobres e muito mais carentes da prestação de serviços com qualidade (BAHL, 2004, p. 2).

Dedicado às causas acadêmicas e líder desde a fase de estudante, o professor Miguel Bahl foi Presidente do Centro Acadêmico de Geografia (CAGEO) e do Centro Acadêmico de Turismo (CAT). Em ambos trabalhou para completar aquilo que considerava faltar nos Cursos.

Em 1986 iniciou sua atividade na UFPR como professor 20 horas (admitido em Concurso Público, aprovado em primeiro lugar dentre onze candidatos). O professor Miguel Bahl foi o primeiro egresso do curso de Turismo da UFPR a ser aprovado como professor (1986), numa época em que era o único docente com formação específica em um curso que iniciou as atividades em 1978.

Posteriormente, sentindo a necessidade de buscar maior formação profissional, o professor Miguel Bahl se direcionou para cursar mestrado e doutorado. Este foi um momento importante, pois fez os cursos na Universidade de São Paulo, indo e vindo toda semana, mas ao mesmo tempo vivenciando uma das maiores cidades do mundo, uma das universidades brasileiras de maior prestígio, e convivendo com os principais especialistas do Turismo do Brasil, dentre os quais seus orientadores, o professor Mario Carlos Beni, no mestrado (concluído em 1994), e o professor Wilson Abrahão Rabahy, no doutorado (concluído em 2000).

Em 1999, criou e coordenou o curso de pós-graduação no nível de Especialização em Planejamento e Gestão do Turismo. Esse curso serviu como base para a futura implantação do Programa de Pós-graduação em Turismo, do qual também participou desde sua concepção, tendo sido vice-coordenador de 2013 a 2015, e Coordenador de 2015 a 2019. Ainda no tocante à administração, exerceu o cargo de Chefe do Departamento de Comunicação Social e Turismo (DECOMTUR) de 1993 até 1999, e Chefe e Suplente de Chefe do Departamento de Turismo (DETUR) em diversos mandatos desde os anos 2000. 
Ao assumir o DECOMTUR lutou pela ampliação de vagas docentes para o Turismo, até que no ano 2000 foi criado o DETUR e, na sequência, houve também a separação física dos dois departamentos. Segundo ele "a criação do DETUR foi de vontade institucional e de reconhecimento às necessidades específicas da área, o que nos propiciou assento no Conselho Setorial e autonomia na busca de pleitos em outras instâncias" (BAHL, 2004, p. 3). Em verdade, o professor Miguel foi modesto e diplomático, pois a existência do Departamento de Turismo se deve à sua liderança e esforço insistente junto à administração da UFPR para demonstrar a importância da criação do DETUR. O professor Miguel Bahl também foi Coordenador do Curso de Turismo no período de 1998 até 2000, quando teve a felicidade de verificar que o curso de Turismo alcançou o maior número de candidatos/vaga no Concurso Vestibular UFPR do ano 2000.

Docente junto ao curso de graduação em Turismo e nos Programas de Mestrado em Turismo e de Mestrado e Doutorado em Geografia, ao longo de sua trajetória acadêmica o professor Miguel também atuou em inúmeros projetos de extensão e de pesquisa junto à UFPR. Em tais projetos o objetivo sempre esteve vinculado ao de integrar teoria e prática, desenvolver uma área ainda carente de estudos e pesquisas mais aprofundadas e de inserção dos alunos em tais atividades.

Ele coordenou ainda um Termo de Cooperação entre a UFPR e a Berufsakademie (Ravensburg - Baden - Würtemberg - Alemanha), e possibilitou o intercâmbio de mais de trinta estudantes alemães em Curitiba e a ida do mesmo número de estudantes brasileiros para a Alemanha, além de recepcionar professores e viajar para a Alemanha. Foi Presidente da Associação Brasileira de Bacharéis em Turismo - Secção Paraná e da ABBTUR Nacional. Enquanto Presidente Nacional conseguiu junto ao Ministério da Educação a criação da Comissão de Especialistas de Ensino de Turismo, que foi um marco para a categoria, e dela posteriormente participou como conselheiro. Ele integrou ainda os Comitês Assessores da Secretaria de Ensino Superior, do Ministério da Educação (SESu/MEC), e do Instituto Nacional de Estudos e Pesquisas Educacionais (INEP).

O professor Miguel fundou em 2005 o grupo de pesquisa Turismo e Sociedade (CNPq), do qual era o líder. E em 2012, realizou Estágio de Pós-Doutorado junto à Universidade de Girona (Espanha), sob orientação do professor Lluís Mundet i Cerdan. Como resultado de sua atuação publicou mais de uma centena de artigos científicos em 
periódicos nacionais e internacionais, livros, capítulos de livros e trabalhos em anais de eventos. Na mesma proporção o professor Miguel Bahl orientou trabalhos de graduação, monografias de especialização, bolsistas de extensão e iniciação científica, bem como dissertações de mestrado, teses de doutorado e supervisões de pós-doutorado. Os principais temas em que atuava eram: turismo, sociedade, cultura e desenvolvimento; planejamento turístico; produção e transformação do espaço urbano e regional; território, cultura e representação; turismo e esporte; turismo e educação; legados étnicos e turismo; e elaboração de roteiros turísticos.

Ele participou de inúmeras comissões e bancas examinadoras de diversos níveis: teses de doutorado; dissertações de mestrado; de monografias de especialização, de concursos públicos e de avaliação de estágio probatório, dentre outras. Foi membro do Conselho de Curadores da UFPR, órgão de deliberação superior destinado a exercer a fiscalização econômico-financeira da Universidade.

Proferiu várias palestras e organizou eventos nacionais e regionais. Dentre os eventos se destacam o Ato Comemorativo aos Quarenta Anos do Curso de Turismo (2018) e as vinte e cinco edições da Semana Paranaense de Turismo (Sepatur). Inicialmente denominada Encontro Paranaense de Turismo, a Sepatur foi organizada pelo professor Miguel ao longo de mais de duas décadas envolvendo a comunidade acadêmica e agentes externos com uma programação composta por palestras, minicursos, apresentação de trabalhos técnico-científicos, visitas técnicas e apresentações socioculturais.

Ao longo destes anos de UFPR recebeu homenagens e distinções de diversas ordens, seja como professor homenageado nas Solenidades de Colação de Grau, como Presidente de Honra de Eventos ou como Mérito por serviços prestados em instituições correlatas. Dentre elas, foi-lhe outorgado pela Associação Nacional de Pesquisa e PósGraduação em Turismo, no XI Seminário da Anptur, ocorrido em 2014, na cidade de Fortaleza (Ceará, Brasil), o prêmio de Pesquisador Emérito. Em 2018 ele também recebeu o prêmio Mérito de Humanidades concedido pelo Setor de Ciências Humanas (SCH) da UFPR na comemoração dos 80 anos do SCH.

Como turismólogo e professor, o Miguel sempre buscou se apropriar de conhecimentos por meio da educação não formal, priorizando viajar. Nas viagens, registrou hábitos, costumes, etnias na busca de compreender a contribuição dos diferentes 
migrantes que ocuparam e ocupam o território nacional brasileiro. Para ele a cultura da sociedade era um fator essencial para o turismo. Assim, o planejamento anual para viajar, conhecer lugares diferentes e vivenciar experiências de lazer, aventura, esportivas, de contato com a natureza era sua prática. Dessa maneira, viajou e conheceu todos os estados brasileiros e quase setenta países. Viajar pelos diferentes espaços brasileiros e pelos diferentes continentes do planeta foi sempre uma grande motivação do Miguel, tendo em vista a ampliação de conhecimento que as viagens proporcionavam. Ele relatava aos amigos que essa experiência lhe permitia uma maior segurança ao dar exemplos em suas aulas de espaços turísticos que vivenciava de fato. E sentia grande alegria ao voltar e compartilhar com seus alunos e colegas de trabalho as observações realizadas.

O professor Miguel Bahl exerceu de forma exemplar suas atividades profissionais na UFPR, considerando-as prioritárias em sua vida, tornou-se referencial e possibilitador para o desenvolvimento de alunos e professores. Por isso sempre buscou abrir portas e trazer inovações, seja na concepção de eventos, nas reformulações curriculares, na busca de vagas docentes, na proposição do curso de especialização e de mestrado, na busca de espaço físico e em outras atividades de interesse para a comunidade universitária. Dessa maneira, ele contribuiu para a área de Turismo e para a sociedade em geral por meio das diversas responsabilidades assumidas ao longo dos anos, enquanto formador, educador, pesquisador e dirigente.

A sua partida deixou a área do Turismo, em especial a da UFPR, como uma orquestra sem maestro. E nas palavras do maestro Rodrigo Toffolo (2019), a orquestra sem o maestro sabe exatamente o que fazer, mas ele tem o papel de harmonizar suas atividades, dando segurança a todos. Nós, pesquisadores do grupo Turismo e Sociedade, encontraremos essa segurança nos princípios deixados pelo estimado professor Miguel Bahl, dentre os quais: a responsabilidade com os deveres, a observância dos detalhes, o respeito à tradição, a manifestação sincera, o senso de justiça, tudo isso sem perder o bom humor e o encantamento pela diversidade da cultura humana e pela beleza da vida.

Assim, seus ensinamentos e sua postura são muito bem sintetizados em duas de suas frases: “Agradeço a Universidade Federal do Paraná pelas oportunidades e vivências que me oportunizou enquanto ser humano e professor"; e "O mundo é muito grande e nossa vida pode ser muito curta. Melhor não ficar pensando nisso e viajar...”. 


\section{Referências}

BAHL, M. Memorial Descritivo - Concurso Público de Provas e Títulos na Classe de Professor Titular na Área de Turismo. Universidade Federal do Paraná, 2004.

BAHL, M. Currículo Lattes. Disponível em: http://lattes.cnpq.br/2467559186292051. Conselho Nacional de Desenvolvimento Científico e Tecnológico. Acesso em: 6 out. 2019.

TOFFOLO, R. Qual a importância do maestro? Disponível em: http://www.orquestraouropreto.com.br/site/qual-a-importancia-do-maestro/. Acesso em: 6 out. 2019. 